\title{
O uso do aloe vera como coadjuvante no tratamento periodontal
}

\author{
The use of aloe vera as an adjunct in periodontal treatment \\ El uso de aloe vera como coadyuvante en el tratamiento periodontal
}

Adriano Flores da Silva

ORCID: https://orcid.org/0000-0001-7515-4088 Universidade Estadual da Paraíba, Brasil

E-mail: floresuepb@gmail.com

Erika Thaís Cruz da Silva

ORCID: https://orcid.org/0000-0002-8475-7929 Universidade Estadual da Paraíba, Brasil E-mail: erika-thais-silva@hotmail.com

Suellen Rabelo Rocha da Costa

ORCID: https://orcid.org/0000-0003-0841-2061 Universidade Estadual da Paraíba, Brasil E-mail: suellenrabelo@hotmail.com.br

Priscila Lima Bezerra

ORCID: https://orcid.org/0000-0003-2458-498X Universidade Estadual da Paraíba, Brasil E-mail: eupriscilalimabe@gmail.com

Aretha Helen Aragão Lourenço

ORCID: https://orcid.org/0000-0001-8851-3473 Universidade Estadual da Paraíba, Brasil E-mail: arethaaragao6@gmail.com Ítalo de Macedo Bernardino

ORCID: https://orcid.org/0000-0003-4750-5666 Universidade Estadual da Paraíba, Brasil E-mail: ítalo.macedo50@gmail.com

\begin{abstract}
Resumo
Objetivo: Revisar os estudos mais atuais na literatura sobre a eficácia da Aloe Vera como coadjuvante no tratamento periodontal. Material e Métodos: Foram selecionados artigos científicos publicados entre os anos de 2013 e 2019 , através dos bancos de dados PubMed e Google Scholar com os seguintes descritores em português e inglês respectivamente, "Gengivite (Gengivitis)", "Periodontite (Periodontitis)", “Aloe (Aloe)", "Medicamentos Fitoterápicos (Phytotherapeutic Drugs)", "Periodontia (Periodontics)" e "Odontologia (Dentistry), escolhidos mediante consulta nos Descritores de Ciências da Saúde - DECs da BIREME. Resultados: A Aloe Vera é uma planta medicinal com ações semelhantes ao da Clorexidina e superior a outros fitoterápicos na diminuição dos sinais clínicos das doenças periodontais. Conclusão: A Aloe Vera é um medicamento fitoterápico com propriedades antibacterianas e anti-inflamatórias, comprovado através de testes clínicos e laboratoriais, capaz de agir com segurança na diminuição dos patógenos periodontais e, por isto, é eficaz como coadjuvante no tratamento periodontal.
\end{abstract}

Palavras-chave: Gengivite; Periodontite; Medicamentos Fitoterápicos; Aloe.

\begin{abstract}
Objective: To review the most current studies in the literature on the efficacy of Aloe Vera as an adjuvant in periodontal treatment. Material and Methods: We selected scientific articles published between 2013 and 2019 through the PubMed and Google Scholar databases with the following descriptors in Portuguese and English respectively, "Gingivitis (Gengivitis)", "Periodontitis (Periodontitis)", "Aloe (Aloe)", "Phytotherapeutic Drugs", "Periodontics (Periodontics)" and "Dentistry (Dentistry), chosen by consulting the BIREME Health Sciences Descriptors - DECs. Results: Aloe Vera is a medicinal plant with actions similar to chlorhexidine and superior to other herbal medicines in reducing the clinical signs of periodontal diseases. Conclusion: Aloe Vera is a herbal medicine with antibacterial and anti-inflammatory properties, proven through clinical and laboratory tests, able to act safely in the reduction of periodontal pathogens and, therefore, is effective as an adjunct in periodontal treatment.
\end{abstract}

Keywords: Gengivitis; Periodontitis; Phytotherapeutic; Aloe.

\section{Resumen}

Objetivo: Revisar los estudios más actuales en la literatura sobre la efectividad del Aloe Vera como coadyuvante en el tratamiento periodontal. Material y Métodos: Se seleccionaron artículos científicos publicados entre los años 2013 y 
2019, a través de las bases de datos PubMed y Google Scholar con los siguientes descriptores en portugués e inglés respectivamente, "Gingivitis (Gengivitis)", "Periodontitis (Periodontitis)", "Aloe (Aloe)", "Fármacos Fitoterápicos", "Periodoncia (Periodoncia)" y "Odontología (Odontología), elegidos mediante consulta con Descriptores de Ciencias de la Salud - BIREME DECs. Resultados: El Aloe Vera es una planta medicinal con acciones similares a la de la Clorhexidina y superior a otras medicinas a base de hierbas en la reducción de los signos clínicos de las enfermedades periodontales. Conclusión: El Aloe Vera es una planta medicinal con propiedades antibacterianas y antiinflamatorias, comprobadas a través de pruebas clínicas y de laboratorio, capaz de actuar de forma segura en la reducción de patógenos periodontales y, por ello, es eficaz como coadyuvante en el tratamiento periodontal.

Palabras clave: Gingivitis; Periodontitis; Hierbas medicinales; Áloe.

\section{Introdução}

A gengivite induzida por biofilme dental e a periodontite são as doenças periodontais mais prevalentes e ambas ocorrem através de uma inflamação crônica de origem infecciosa. A primeira se caracteriza por ser uma reação inflamatória que apresenta vermelhidão, sangramento e inchaço da gengiva (Caton et al., 2018). Enquanto a periodontite é evidenciada por uma destruição progressiva dos tecidos de inserção dental (Steffens, Marcantonio, 2018).

Cerca de 700 espécies de bactérias já foram encontradas no microbioma da cavidade oral (Lemos, 2016). Estas bactérias, quando não se encontram em simbiose com o hospedeiro, resultam em diversas doenças bucais, como a periodontite (How, Song et al., 2016). O biofilme evolui conforme a organização dos microrganismos presentes, iniciando por uma película adquirida, podendo chegar a formação do tártaro subgengival (Hung, 2015).

Quando o biofilme e os patógenos periodontais são eliminados, os tecidos periodontais são normalizados, porém, essa inflamação, mesmo sendo reversível, fragiliza os componentes do periodonto, podendo levar a problemas mais graves como a perda óssea (Soares, 2019). Assim, o controle do biofilme supragengival é fator decisivo para o sucesso terapêutico periodontal em longo prazo, visto que apenas o controle profissional, sem um adequado padrão de higiene oral pelos pacientes, é ineficaz (Angst, Gomes e Oppermann, 2015).

Os enxaguatórios bucais, também denominados de colutórios, representam a forma de controle químico de mais fácil acesso (Araújo et al., 2015). Os compostos mais utilizados são: A clorexidina, considerada o padrão ouro na odontologia, o triclosan, também com ação anti-inflamatória, os óleos essenciais, que alteram a higidez da parede celular das bactérias e o Flúor, muito conhecido e presente nos dentifrícios (Araújo et al., 2015; Tanganho, 2015).

$\mathrm{Na}$ odontologia, a fitoterapia ainda é pouco utilizada, mas já é realidade a adição de plantas medicinais a dentifrícios e enxaguantes bucais que são capazes de reduzir os microrganismos da cavidade oral (Molina et al., 2008). Um estudo ressaltou a importância de 24 espécies vegetais utilizadas na Odontologia que possuem efeitos de anestésico tópico, ansiolítico, antifúngico, anti-inflamatório, dentre outros (Monteiro, 2014).

A Aloe Vera, popularmente chamada de babosa, é um desses fitoterápicos, com ação anti-inflamatória e antioxidante (Oliveira, 2008). Ela já era citada como planta medicinal em diversas culturas antigas, a exemplo do Egito, onde ficou conhecida como a "planta da imortalidade", usada por Cleópatra para cuidar da pele e dos cabelos (Freitas, Rodrigues e Gaspi, 2014).

A literatura odontológica apresenta alguns estudos onde a eficácia do Aloe Vera, na redução da gengivite e do biofilme, é bastante satisfatória. Um exemplo, é a pesquisa realizada por Khatri et al., (2014), onde evidenciaram a superioridade de um creme dental contendo Aloe Vera contra um que continha Triclosan. O composto a base de Aloe Vera diminuiu a gengivite de forma mais efetiva. Sendo assim, este trabalho tem como objetivo revisar os estudos mais atuais na literatura sobre a eficácia do Aloe Vera como coadjuvante no tratamento periodontal. 


\section{Metodologia}

Este estudo caracterizou como uma revisão de literatura do tipo narrativa, desenvolvida a partir da busca de artigos científicos com os seguintes descritores em português e inglês respectivamente, "Gengivite (Gengivitis)", "Periodontite (Periodontitis)", "Aloe (Aloe)", "Medicamentos Fitoterápicos (Phytotherapeutic Drugs)", "Periodontia (Periodontics)" e “Odontologia (Dentistry), escolhidos mediante consulta nos Descritores de Ciências da Saúde - DECs da BIREME, nas bases bibliográficas PubMed (Us National Library of Medicine) e Google Scholar. A pesquisa foi realizada nos meses de agosto e setembro de 2019 e os trabalhos foram selecionados com base em sua relevância e grau de evidência científica, mediante leituras e análises críticas, contribuindo para o processo de síntese e análise dos resultados de vários estudos e criando um corpo de literatura compreensível sobre o tema estudado.

\section{Resultados e Discussão}

O cravo-da-índia, a camomila, a malva, a romã, a unha-de-gato e a própolis, foram listados como os fitoterápicos mais utilizados na Odontologia (Mota et al., 2018). A sua eficácia foi comprovada, após eles passarem por testes clínicos e laboratoriais, onde suas propriedades foram analisadas. Além desses que foram citados, Safiaghdam et al., (2018), em outra pesquisa, dizem que a Aloe Vera, também é uma planta medicinal que apresenta um conjunto de evidências que comprovam sua eficiência na gengivite.

O extrato de própolis indiano passou por avaliação clínica e microbiológica, para verificar sua eficácia no tratamento da periodontite. Foram selecionados vinte pacientes com periodontite crônica e que tivessem ao menos duas bolsas periodontais com profundidade de sondagem maior que $5 \mathrm{~mm}$. As bolsas periodontias que receberam o extrato de própolis como complemento a raspagem e alisamento radicular (RAR), tiveram uma melhora superior aos locais que passaram apenas pela RAR. Diante disso, fica claro a importância do extrato de própolis como complemento no tratamento periodontal (N sanghanI, Bm e S, 2014).

Escolares entre nove e doze anos participaram de um estudo onde, um enxaguatório bucal a base de romã e um que continha clorexidina, foram avaliados e descobriu-se que ambos foram efetivos na diminuição do Índice de Sangramento a Sondagem, mas que a clorexidina foi mais efetiva na redução do índice de placa. Com base nestes resultados, sugere-se a utilização do fitoterápico como coadjuvante no tratamento periodontal por mostrar eficácia e segurança durante todo o período em que os testes foram feitos (Silva, 2014).

A camomila foi tão eficiente quanto a clorexidina na diminuição da inflamação gengival em pacientes que realizaram bochechos à base de extrato de camomila e que eram portadores de gengivite crônica e na redução de patógenos em pacientes com periodontite, quando a planta foi usada como tratamento de apoio. Sendo assim, a camomila comprovou suas atividades anti-inflamatórias e antimicrobianas, podendo ser recomendada para a preservação de uma gengiva saudável (Zanca et al., 2016).

Bochechos à base de extratos de camomila e aroeira foram testados, comparando-os com a clorexidina. Os pacientes participantes desse estudo, que teve uma duração de quinze dias, apresentavam gengivite crônica. Todos os três bochechos foram eficazes na redução dos Índices de Sangramento Gengival e de Placa, porém a redução do Índice de Placa foi maior com o extrato de camomila, e o de aroeira obteve a menor redução (Lins et al., 2013).

Em uma revisão de literatura, realizada nas bases de dados Scielo e Pubmed, dez trabalhos foram selecionados levando em consideração os benefícios da aroeira no tratamento periodontal. Com base nos seus resumos foi verificado que a maioria dos estudos traziam alguma vantagem para os pacientes que precisavam de tratamento periodontal, visto as ações antiinflamatória, antimicrobiana, cicatrizante, analgésica e antirreabsortiva da aroreira (Cavalcante et al., 2018). 
A efetividade da própolis frente à clorexidina, em relação à redução da placa bacteriana, é inferior, porém ela pode ser mais eficaz na redução da inflamação gengival (Mendonça et al., 2016). Foram realizados testes com um enxaguante bucal contendo própolis, um com clorexidina e outro com solução salina, em indivíduos separados em três grupos, realizando bochechos duas vezes ao dia, por cinco dias, para a obtenção dos resultados citados acima.

A Uncaria Tomentosa, popularmente chamada de unha-de-gato, foi avaliada em culturas de células e apresentou ação antiviral e anti-inflamatória (Signori e Correa, 2015). A malva é citada por Gonçalves et al., (2014) no tratamento de gengivites, na inflamação e infecção dentária. E o extrato do cravo-da-índia, para Affonso et al., (2012), tem ação semelhante à dos anti-inflamatórios não esteroidais (AINES), após testes realizados com ratos. No entanto, estes fitoterápicos apresentam poucos testes que comprovam sua eficácia como agentes terapêuticos auxiliares no tratamento periodontal.

Quando se comparou a eficácia da clorexidina com o triclosan, utilizando a participação de 26 voluntários, divididos em dois grupos, realizando bochechos diários, duas vezes ao dia, por uma semana, verificou-se que ambos apresentaram ação antimicrobiana, no entanto, o bochecho com clorexidina teve uma redução maior de microrganismos. Com este estudo, ficou comprovado que os dois enxaguatórios bucais podem ser utilizados, associados ao controle mecânico, para diminuição do biofilme (Vaz, 2014).

O dióxido de cloro, a clorexidina e a Aloe vera, passaram por um estudo parecido com o anterior, onde foram comparados entre si. Um total de 85 participantes, portadores de aparelho ortodôntico fixo, divididos aleatoriamente em três grupos (dióxido de cloro, clorexidina e Aloe vera), com duração de quinze dias, tiveram o índice de placa e escores gengivais avaliados. Todos apresentaram uma redução significativa no índice de placa e escores gengivais, mas a clorexidina, quando comparada com a Aloe Vera, teve um desempenho superior, no entanto nenhuma diferença foi observada em relação ao dióxido de cloro (Yeturu et al., 2016).

Quarenta e cinco pacientes, que apresentavam gengivite induzida por placa dental participaram de um estudo, onde eles foram divididos em três grupos de 15 pessoas, e o teste durou três meses. O grupo 1 utilizou $10 \mathrm{ml}$ de um exaguatório de aloe vera, realizando bochechos uma vez ao dia, o segundo passou apenas por raspagem e alisamento radicular (RAR) e o grupo três, além do bochecho com aloe vera, foi submetido ao RAR. Todos tiveram uma redução significativa da inflamação gengival, mas os pacientes que utilizaram a aloe vera tiveram uma redução maior. Assim, observa-se uma propriedade antiinflamatória significativa neste fitoterápico, podendo ser utilizado para complemento na redução da gengivite (Ajmera, Chatterjee e Goyal, 2013).

Um gel contendo aloe vera foi utilizado em vinte pacientes que apresentavam periodontite crônica de moderada a grave. O objetivo era avaliar a eficácia do fitoterápico associado ao RAR, quando foi avaliado o índice de placa (IP), índice gengival (IG) e profundidade de sondagem (PS) desses pacientes. Eles receberam, em um dos quadrantes, apenas a RAR (grupo controle) e no outro quadrante, a RAR combinado com o gel de Aloe Vera (grupo experimental). No (IP) não houve diferença entre os grupos, quanto ao (IG), ocorreu uma melhora significativa nos dois quadrantes, com destaque para o grupo experimental, que também se destacou em relação a (PS). A partir desse estudo foi possível chegar à conclusão de que o gel de aloe vera, combinado com a RAR, é eficaz para o tratamento da periodontite crônica (Moghaddam et al., 2017).

Um estudo com o Aloe Vera, que utilizou a participação de 300 indivíduos, durante quatro dias, divididos em três grupos: grupo que utilizou a Aloe Vera, o grupo controle que utilizou clorexidina a $0,2 \%$ e o grupo placebo, com solução de água salina. O enxaguatório com Aloe Vera teve o mesmo resultado na diminuição do índice de placa, quando comparado com a clorexidina e ambos foram superiores ao grupo placebo. Os resultados desse estudo indicam que o enxaguatório com Aloe Vera, pode ser indicado para a redução da placa dentária (Gupta et al., 2014).

Quem chegou a um resultado bem parecido com o estudo citado acima, foram B et al., (2014), quando avaliaram a eficácia de um exaguatório de aloe vera na placa dental e na gengivite, comparando-o com a clorexidina caracterizada como 
grupo controle, e com a água destilada, definida como o grupo placebo. O estudo durou 30 dias, contou com a participação de 345 participantes, divididos em três grupos de 115 pacientes, cada um fazendo bochechos duas vezes ao dia, com um dos três compostos. Foi notório uma redução significativa nos índices de sangramento gengival e de placa, no grupo da Aloe Vera e no grupo controle em relação ao grupo placebo. O enxaguatório bucal com Aloe Vera, além de não mostrar efeitos colaterais como a clorexidina, reduziu os índices periodontais, podendo ser utilizado com segurança.

O uso de enxaguatórios bucais com aloe vera e óleo de tea tree, também conhecido nacionalmente como óleo de melaleuca, pode auxiliar na diminuição da placa bacteriana, da gengivite e S. mutans na cavidade oral, além disso, a ação desses dois agentes é igual à da clorexidina. $\mathrm{O}$ estudo foi realizado com 89 meninos e 63 meninas entre 8 e 14 anos, com duração de 6 semanas, onde os participantes foram divididos em quatro grupos, usando um dos colutórios: Aloe vera, clorexidina, óleo de tea tree e grupo placebo. Com isto, em mais um estudo, fica claro a eficácia do aloe vera como fitoterápico capaz de agir na diminuição da inflamação gengival (Kamath et al., 2019).

Uma revisão sistemática, contendo seis ensaios clínicos, onde 1358 indivíduos foram incluídos, avaliou a eficácia do enxaguatório bucal com aloe vera na placa e na inflamação gengival. Todos os trabalhos mostraram que o agente estudado reduziu a placa bacteriana e a inflamação gengival. Quatro artigos mostraram que o fitoterápico é tão eficaz quanto a clorexidina na redução da placa, e dois falaram o contrário. Quando o assunto é inflamação, três estudos revelaram resultados comparáveis entre aloe vera e clorexidina e apenas um falou da superioridade da clorexidina. Um outro ponto muito positivo do Aloe Vera, é que diferente da clorexidina, ela não apresenta efeitos colaterais, como mancha nos dentes e alteração da sensação gustativa (Al-Maweri et al., 2019).

\section{Conclusão}

O desenvolvimento do presente estudo possibilitou uma análise de como a Aloe Vera é eficaz como coadjuvante no tratamento periodontal, visto suas ações antibacteriana e anti-inflamatória, clinicamente comprovadas, possibilitando que este fitoterápico possa ser utilizado com segurança, sem trazer efeitos colaterais para os pacientes. Diante disso, podemos observar que, associado ao controle mecânico da placa dental, os colutórios a base de Aloe Vera, principalmente são capazes de intervir nos sinais clínicos da doença periodontal, contribuindo para uma saúde gengival melhor.

\section{Referências}

Affonso, R. S. et al. (2012). Aspectos Químicos e Biológicos do Óleo Essencial de Cravo da Índia. Revista Virtual de Química, 2(4), 146-161.

Ajmera, N., Chatterjee, A., \& Goyal, V. (2013). Aloe vera: It's effect on gingivitis. Journal Of Indian Society Of Periodontology, 17(4), 435-438.

Al-maweri, S. A., et al. (2019). Efficacy of aloe vera mouthwash versus chlorhexidine on plaque and gingivitis: A systematic review. International Journal Of Dental Hygiene, 1(1), 01-21.

Angst, P. D. M., Gomes, S. C., Oppermann, R. V. (2015). Do controle de placa ao controle do biofilme supragengival: o que aprendemos ao longo dos anos? Rev@odonto,69(3), 252-259.

Araújo, D. B., et al. (2015). Saúde bucal: a importância dos enxaguatórios com antissépticos. Revista de Ciências Médicas e Biológicas, 14(1), 88-93.

B, K. et al. (2014). Effect of Aloe vera mouthwash on periodontal health: triple blind randomized control trial. Oral Health Dent Manag. 13(1), 14-19.

Cavalcante, F. R. F., et al. (2018). O potencial adjuvante da aroeira do sertão no tratamento periodontal - revisão de literatura. Anais da Jornada Odontológica dos Acadêmicos da Católica, 4(1), 1-6.

Caton, J. G., et al. (2018). A new classification scheme for periodontal and peri-implant diseases and conditions - Introduction and key changes from the 1999 classification. Journal of Periodontology, 45(20), 41-45.

Freitas, V. S., Rodrigues, R. A. F., \& Gaspi, F. O. G. (2014). Propriedades farmacológicas da Aloe vera (L.) Burm. f. Revista Brasileira de Plantas Medicinais, 16(2), 299-307. 
Gonçalves, Z. A., et al. (2014). Alternativas terapêuticas para tratamento de afecções bucais no idoso. Revista Brasileira de Odontologia do Brasil Central, 66(23), 130-134.

Gupta, R. K. et al. (2014). Preliminary Antiplaque Efficacy of Aloe Vera Mouthwash on 4 Day Plaque Re-Growth Model: Randomized Control Trial. Ethiop J Health Sci, 24(2), 139-144.

How, K. Y., Song, K. P., \& Chan, K. G. (2016). Porphyromonas gingivalis: An Overview of Periodontopathic Pathogen below the Gum Line. Front Microbiol, 53(7), 1-14.

Kamath, N. P., et al. (2019). The effect of aloe vera and tea tree oil mouthwashes on the oral health of school children. European Archives Of Paediatric Dentistry, 1(1), 1-6.

Khatri, S. G. et al. (2017). Antiplaque, Antifungal Effectiveness of Aloevera Among Intellectually Disabled Adolescents: Pilot Study: Oral, Antifungal Efficacy Of Aloevera. Pediatric Dentistry, 39(7), 434-438.

Lemos, A. F. P. O papel da porphyromonas gingivalis nas doenças da cavidade oral e sua relação com doenças sistémicas. (2016). Dissertação (Mestrado em Medicina Dentária) - Instituto Superior de Ciências da Saúde Egas Moniz, Monte de Caparica.

Lins, R., et al. (2013). Avaliação clínica de bochechos com extratos de Aroeira (Schinus terebinthifolius) e Camomila (Matricaria recutita L.) sobre a placa bacteriana e a gengivite. Revista Brasileira de Plantas Medicinais, 15(1), 112-120.

Mendonça, S. M. S., et al. (2016). Própolis na odontologia: uma abordagem de suas diversas aplicabilidades clínicas. Revista Fluminense de Odontologia, 22(46), 1-12.

Molina, F. P., et al. (2008). Própolis, sálvia, calêndula e mamona - atividade antifúngica de extratos naturais sobre cepas de Candida albicans. Cienc Odontol Bras, 11(2), 86-93.

Moghaddam, A. A., et al. (2017). Clinical Evaluation of Effects of Local Application of Aloe vera Gel as an Adjunct to Scaling and Root Planning in Patients with Chronic Periodontitis. Journal Of Dentistry, 18(3), 165-172.

Mota, I. B. O., et al. (2018). Fitoterapia na odontologia: levantamento dos principais produtos fitoterápicos usados para a saúde bucal. Revista Psicologia e Saúde em Debate, 4(1), 71-71.

N Sanghani, N., B. M. S. (2014). Health from the Hive: Propolis as an Adjuvant in the Treatment of Chronic Periodontitis - A Clinicomicrobiologic Study. Journal of Clinical e Diagnostic Research, 8(9), 41-44.

Safiaghdam, H. et al. (2018). Medicinal plants for gingivitis: a review of clinical trials. Iranian Journal Of Basic Medical Sciences, $21(10), 978-991$.

Silva, F. R. S. (2014). Avaliação clínica da efetividade de um enxaguatório (Punica granatum Linn.) sobre o controle de biofilme dentário e inflamação gengival em escolares. Trabalho de Conclusão de Curso (Graduação em Odontologia) - Universidade Estadual da Paraíba, Campina Grande.

Signori, J. V. F., \& Correa, T.W. (2015). Atividade antimicrobiana e identificação de compostos de plantas medicinais de uso popular. Trabalho de Conclusão de Curso (Graduação em Farmácia) - Faculdade de Americana, Americana.

Soares, L. M. S. (2019). A relação entre o estresse e a doença periodontal: uma revisão da literatura. Trabalho de Conclusão de Curso (Graduação em Odontologia) - Universidade Federal de Juiz de Fora, Governador Valadares.

Steffens, J. P., \& Marcantonio, R. A. C. (2018). Classificação das Doenças e Condições Periodontais e Peri implantares 2018: guia Prático e Pontos-Chave. Revista de Odontologia da Unesp, 47(4), 189-197.

Tanganho, A. M. Z. (2015). Agentes de prevenção contra biofilmes dentários. Dissertação (Mestrado em Odontologia) - Instituto Superior de Ciências da Saúde Egas Moniz, Almada.

Vaz, V. T. P. (2014). Comparação do efeito do bochecho de triclosan + copolímero + fluor, com a clorexidina, sobre a taxa de formação da placa dentária, retenção de antimicrobiano na placa dentária e na saliva e redução de estreptococos do grupo mutans na saliva: estudo clínico randomizado, cruzado, duplocego controlado. Dissertação (Mestrado em Odontologia) - Faculdade de Odontologia (foar) - Araraquara.

Yeturu, S. K., et al. (2016). Effect of Aloe vera, chlorine dioxide, and chlorhexidine mouth rinses on plaque and gingivitis: A randomized controlled trial Journal Of Oral Biology And Craniofacial Research, 6(1), 55-59.

Zanca, M. M., et al. (2016). Utilização da camomila (matricaria recutita 1.) para tratamento de gengivite e periodontite. Revista Ação Odonto, 1(1), 40-40. 